\title{
Conceptual Type - a commentary on the Internet's design development?
} - Hypermodal deconstructivism, digital crafting and media-reflexive iconoclasm

Ida Engholm,

Royal Danish Academy of Fine Arts, Schools of Architecture, Design, and Conservation

"Conceptual type" is not a well-defined term. The concept doesn't have any established encyclopedic definition and has not yet served as the subject of a definitional exploration in the literature related to graphic design. When you search the term on Google, links pop up to phrases like "amazing type ideas", "striking typography images", "very catchy types" and the like, where what is primarily in focus is the visually impressive aspect. In this connection, where the topic at hand is conceptual type, it accordingly makes sense to pin down a more precise and analytic definition. Here, by way of introduction, it seems relevant to look at how the term "concept" is being used within cognate specialized fields like "conceptual art" and "conceptual design". Thereafter, the term will be discussed in its relation to the Internet which, as a new medium for design, has served as the jumping-off point for conceptual type and for discussions centered on the relationship between typefaces and the underlying ideas. Within the realm of art history, conceptual art has been the object of various definitions, although this category is based primarily on the viewpoint that art exists first and foremost as idea - or concept - and meaning, and only secondarily as object. ${ }^{1}$ Moreover, conceptual art denotes artistic productions and artistic creations where the concept or the idea, when conjoined with the artwork, is more important than any traditional aesthetic or formal considerations. ${ }^{2}$ In the avant-garde artist Sol LeWitt's celebrated definition, conceptual art is defined as art where all planning and all decisions in connection with artworks are made in advance and where the actual execution is a mechanical issue. "The idea becomes a machine that makes the art", wrote Sol LeWitt in 1967. ${ }^{3}$ More recent interpretations have, moreover, defined conceptual art as art that critically and explicitly asks questions about what it is that can be understood as "art" and what the limits of art are. ${ }^{4}$
In the history of design, "conceptual design" and "critical design" have been collocated and are often used interchangeably to indicate design that, in a conceptually distanced manner, programmatically takes into consideration the design discipline's role in society in relation to, for example, consumption and environmental issues. In critical design, the idea - the formulation of a critique - precedes the manifest expression, even though one branch of critical design, especially as can be seen with some of the more recent tendencies, is also perfectly conscious of its own exterior staging. ${ }^{5}$ In this way, critical design and conceptual art are kindred disciplines and thus also have common historical roots in the 1960s' and the 1970s' design- and art-milieus, where the boundaries between everyday life and art were being rubbed out. If we take our point of departure in the significations mentioned above, we can propose a definition of conceptual type as being a typeface (of one style or size) that communicates a message or idea and that is characterized, above and beyond this, by interrogating or expanding the boundaries of the typeface's own media; that is to say, by examining the boundaries of what a given typeface essentially represents and what that typeface can be used for. We can then define conceptual type as a typeface that is related to the design's salient modes of operation and communicative forms and that embodies a message which transcends the typeface's functional mission. In modern typographical history, type, in several different periods, has been enquiring and experimental. In recent years, both the postmodern and deconstructivist typography have, for example, supplied experimental elements and have served to widen the frameworks for what type design is and for how it can be used. The experiments have been borne forth by a reaction to modernism's function-related principles. Additionally, technological advances have brought forth new premises for typography, conditions on 
which conceptual type has explored and commented. One of the most crucial venues for typographic experiments in recent years has been the Internet which, especially during the formative years of the medium's development, has served as the frame for radical exploration and for typographical innovation, and which is accordingly interesting to deal with in relation to discussing conceptual typography's role today, as it is manifest on the Internet and in the various media of which we avail ourselves.

\section{THE INTERNET AS DESIGN-BASED MEDIUM}

Up until the start of the 1990s, the Internet was exclusively a code- and command-based publishing channel. But with the development of the "worldwide web (www)", it suddenly became possible, also, to publish pictures, sounds and graphic images. It consequently became relevant to become concerned with how the media should be designed. During the incipient years of the Internet's development, it was largely the printed media that set the standard for how to set up websites, while the interface-industry supplied principles for the elaboration of navigation design. The various professions' respective guidelines provided fertile ground for discussions centered on how the new media ought to be designed. In graphic design contexts, books and websites with principles for the design of the "www" were being published; to a great extent, these redressed the printed medium's ideals about readability and functional principles for setting up the texts. These principles largely reflected contemporary discussions going on within the graphic

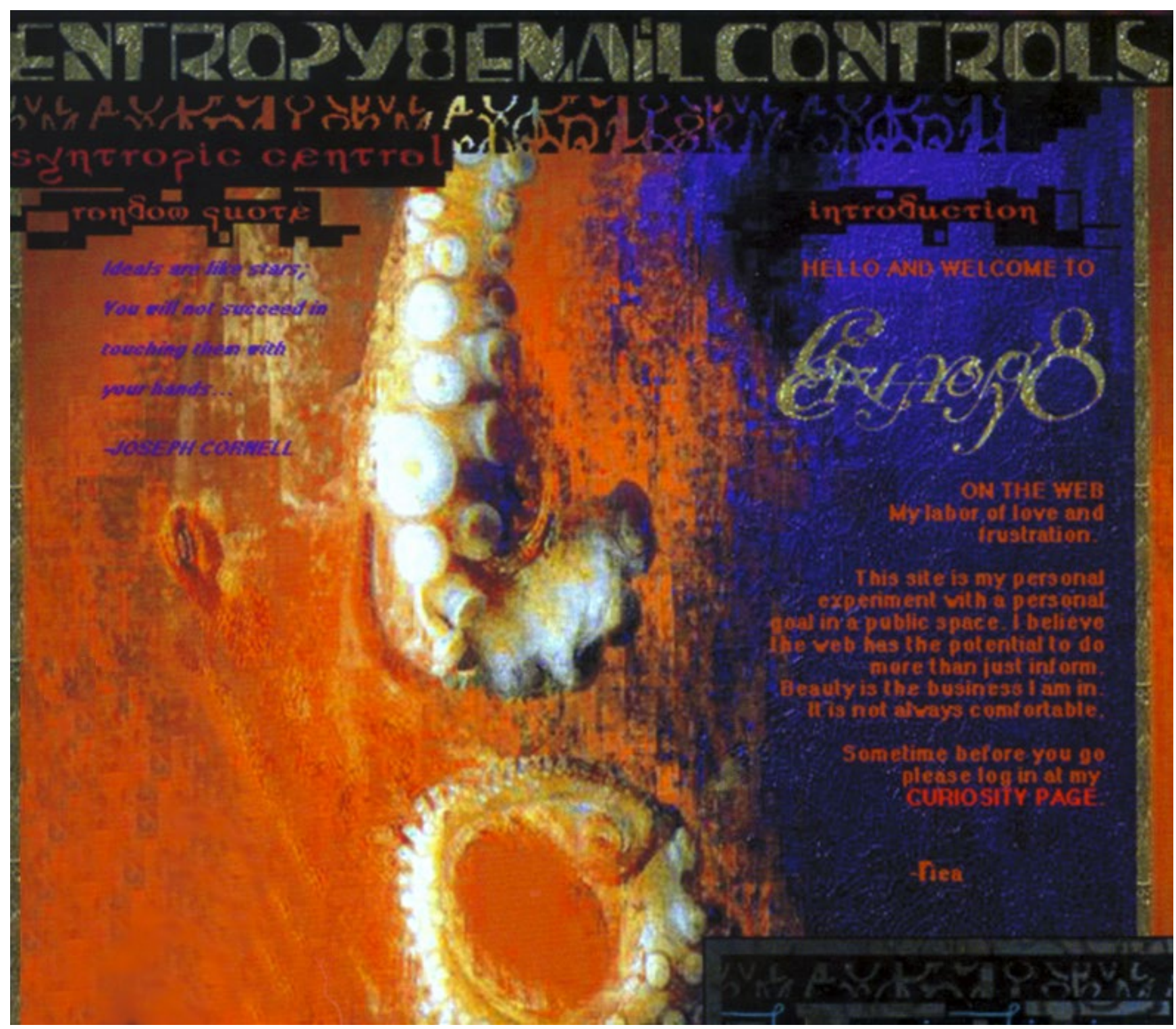

Aurelia Harvey's exotic web territory, entropy8.com, from 1994 is one of the earliest exponents on the Internet for a deconstructivist and self-expressive style that has come to be endowed with designations like "lo-fi grunge" and "trash", by way of reference to the sampled, distorted expression that is based on juxtapositions and collocations of graphically processed elements, "scratched" lettering and illustrations with layer-on-layer textures. 


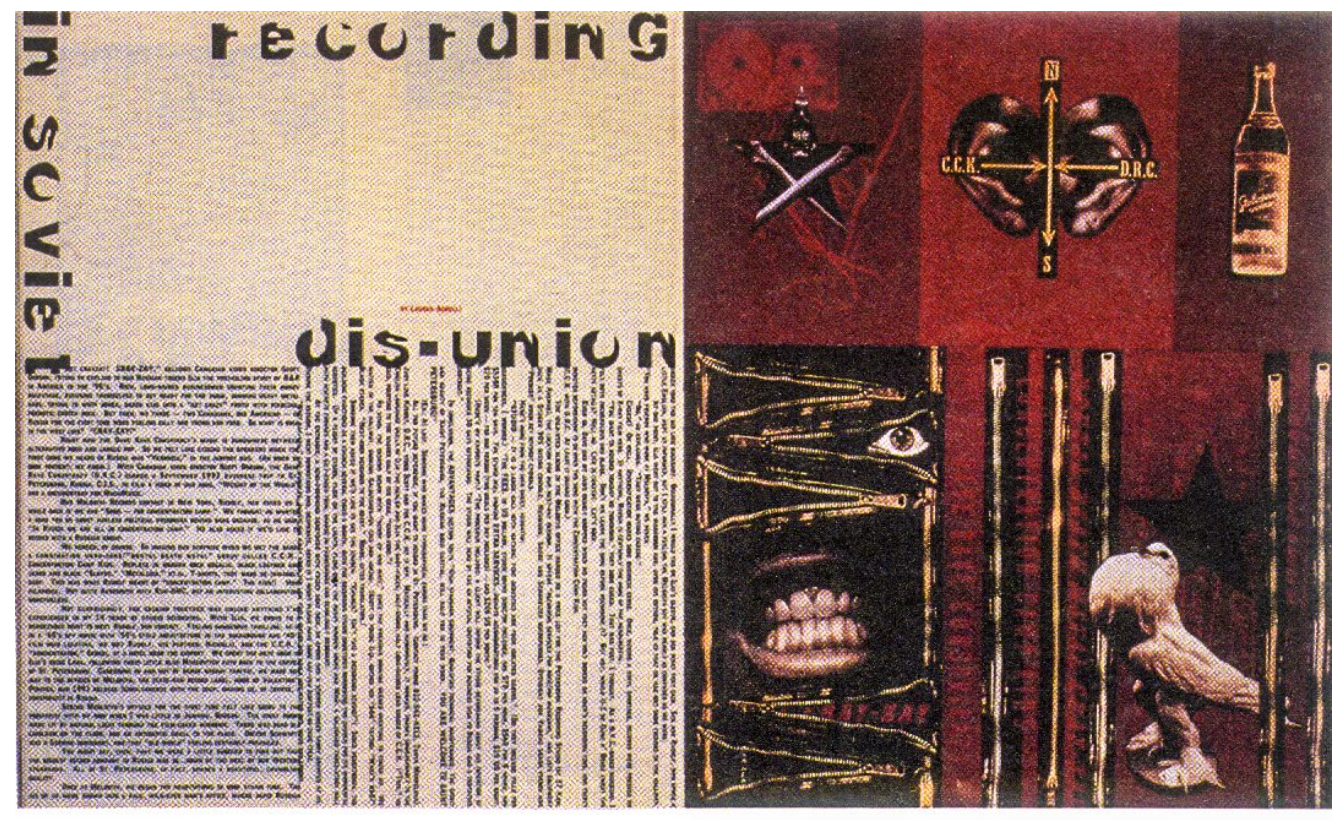

David Carson's spread from Ray Gun, no. 4, March 1993 and no. 14, March 1994. With its painting-like collages consisting of illustrations, photographs, fragments of broken letters and patches of empty white spaces, the magazine was regarded as a leading exponent of postmodernism and deconstructivism in graphic design that, by way of proclamation, dissociated itself from all typographical conventions. In Carson's project, the message was picked to pieces and re-assembled in a novel way that rendered the decoding process difficult and called the viewer into play as an active

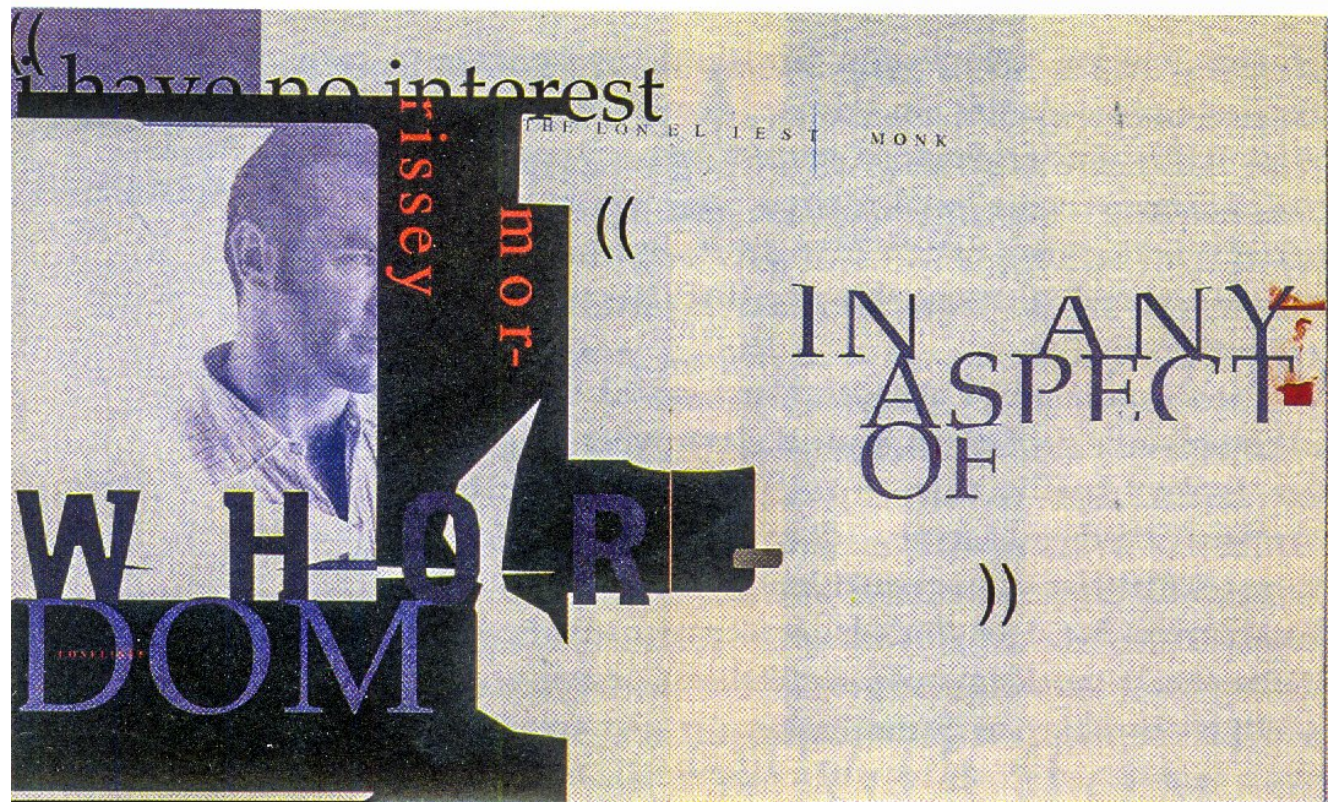
co-creator of the content.

profession between, on the one side, proponents of traditional modernism's functional orientation and, on the other, newer designer-centered and postmodernist ideologies.

The modernist approaches were represented through books such as Mike Zender, Jeff Fine and Rich Albertson's Designer's Guide to the Internet (1995) and Roger Black's Web Sites That Work (1997). As "how-to" books for web development with a graphic point of departure, they pleaded for a continuation of modernist conventions in the design of web pages, including grid-based modular construction and they addressed the demands for clarity and readability in the layout and the choice of typefaces. The modernistic approach found some measure of support among advocates of the interface industry who, with usability-people like Jacob Nielsen in the forefront, similarly presented a "less is more" approach to the Internet, albeit one where the technical-functional consideration - the aim of offering quick and easy access to the contents - was assigned greater priority than any considerations paid to the graphic aspects. According to Nielsen, the graphics could actually stand in the way of a functional interaction. For this reason, resources in the development were primarily supposed to ensure expedient interaction and ought to focus on graphics to a lesser extent.

\section{HYPERMODAL DECONSTRUCTIVISM}

In contrast to this, the proponents of the postmodernist approach argued for placing greater weight on the graphic-aesthetic aspects of web develop- 
ment. The inspiration was drawn from prepress-phase postmodernism's and deconstructivism's showdown with modernism's function-oriented and utility-maximizing approaches effected for the sake of making expressive and artistic-subjective inroads into the further development of type and typography. On the Internet, the postmodern ideologies of designers were expressed by people like Michel de Boer, who dissociated himself from modernism's requirement for a "neutral" presentation of content and applauded, instead, a web based typographical style that would hopefully attract attention on its own terms and would, like art, be "self-expressive". According to De Boer, "design [...] should not be too easy, either to make or to look at. The receiver of the message should be made to work, being forced to think about what he is seeing". Similarly, Rick Poynor, in a prepress context in 1991, suggested that typography's role was supposedly to provoke the reader into becoming an active participant in the construction of the message. Taking his point of departure in the Cranbrook theories

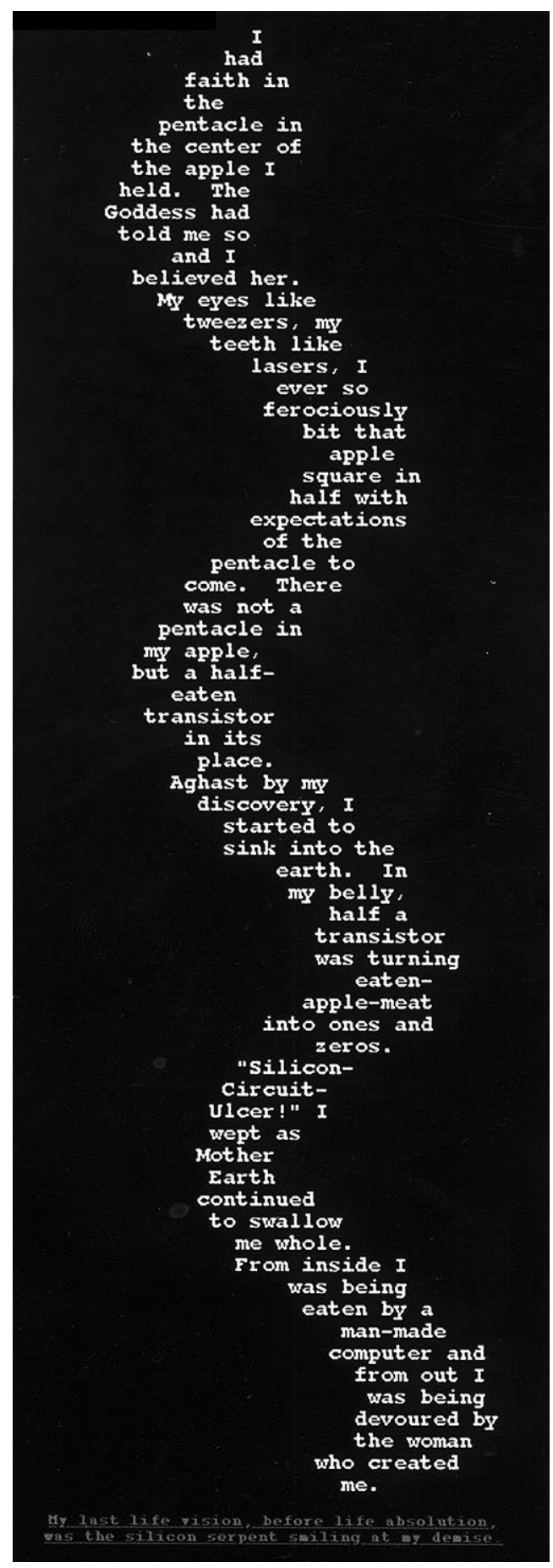

that had been derived from French philosophy and literary theory, the radical typographical arrangement should, according to Poynor, deconstruct, break up and display the manipulated visual language and the different levels of meaning that were inherent in a given design. The visual style that was connected with the these viewpoints could be linked in the printed media to graphic designers like David Carson, Phil Baines, Rudy VanderLands and Zuzanna Licko and to magazines like Beach Culture, Ray Gun and Emigre, which, in different ways, set new agendas on the graphic arts scene in the 1990s. On the Internet, the deconstructivist visual style was represented by experimental graphic artists like Michel de Boer who, taking his inspiration from the printed medium's expressive approaches, sought to transpose a material tactility and artistically-oriented self-expressiveness into a digital context, albeit a context wherein there also lay the seeds of a reckoning with the hegemony of printed matter. The graphics were not merely supposed to express resistance to modernism's principles but

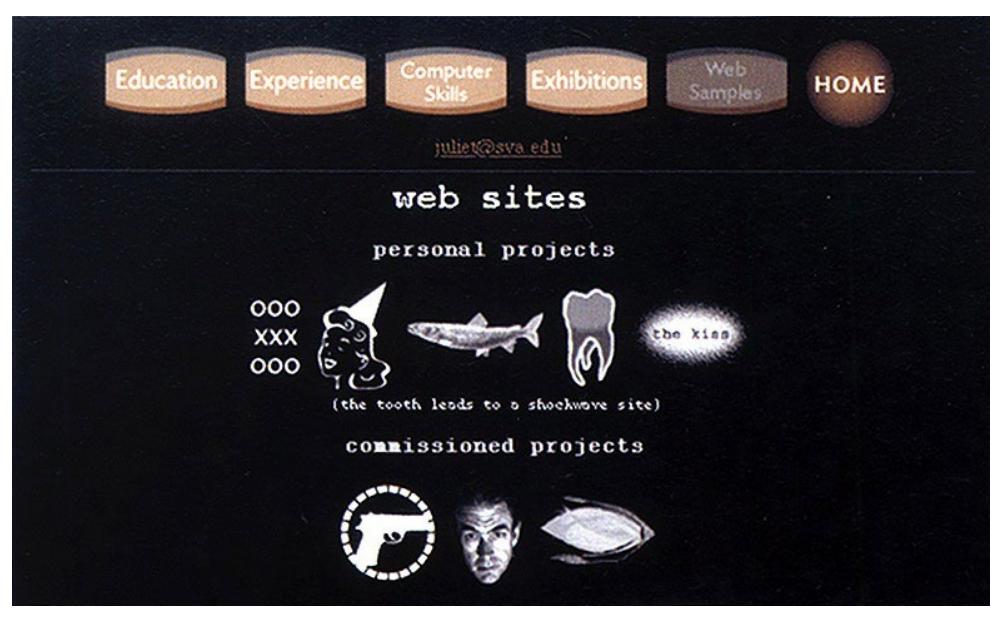

Juliet Martin's website from 1996 was built as an opaque system with different text columns comprised of figurative text passages that spread out like patterns on the page. In the site's layout, there's a hair-fine balance between positive and negative space and visual effects are created that both comment on and bypass the low transmission speeds to which web designers were subject at the time the site was launched. 


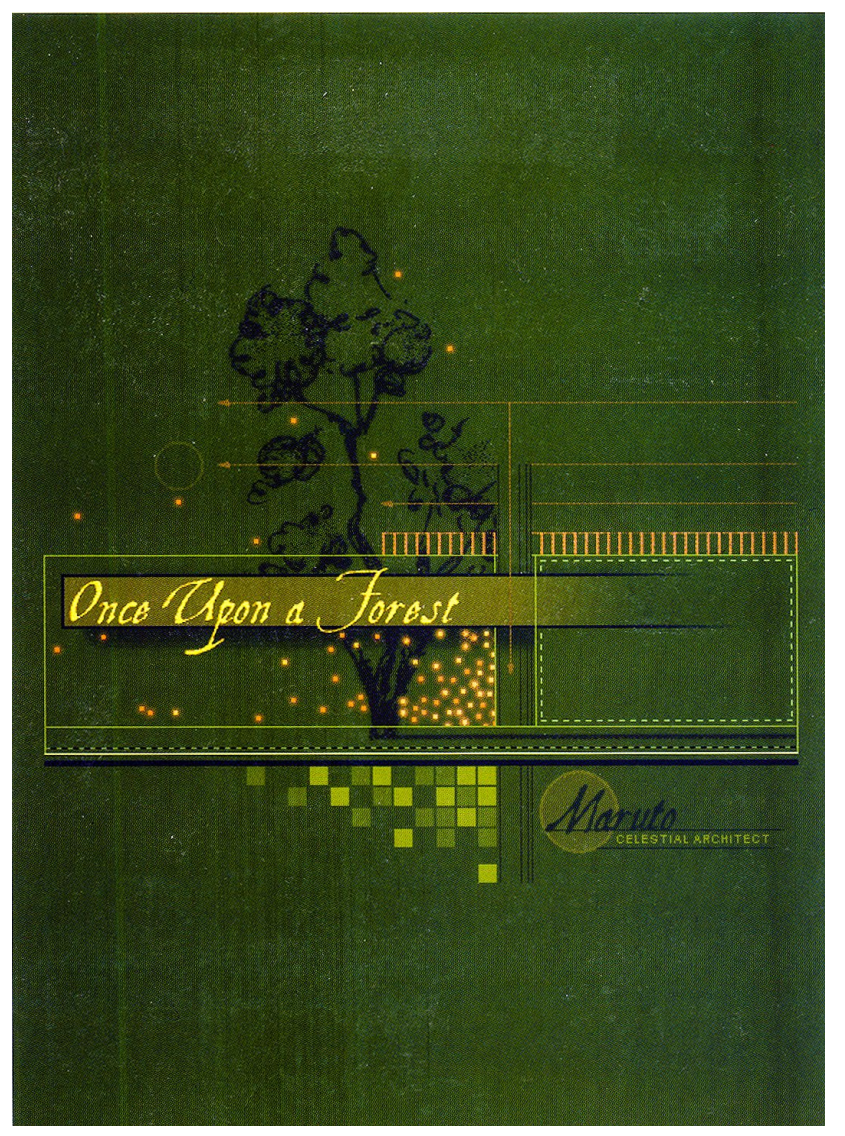

were also expected to underpin the digital medium's hypermodal character. The resistance to the printed medium's modernism also constituted, on the Internet, a showdown with the interface industry's prioritization of technical-functional aspects. Accordingly, the deconstructivist experiments pertained not only to the graphic expression but had also to do with how one could interact in new and different ways when working inside the new media. The experiments were given names like "lo-fi grunge", with a nod to David Carson's "loose, antigrid layouts" or "trash", with reference to the fact that the graphic elements had been gathered from different contexts, as "dirt and filth" that were inserted into an artistic compilation and with an interaction that was muddy and opaque. One example of what could be called "hypermodal deconstructivism" was graphic

Joshua Davis' sites, Once Upon a Forest and Praystation served, in the late 1990s, as the frame for code-based experiments, as a vehicle for circumventing limitations in the browsers and 'html'-codes, and as the springboard for a radical exploration of the medium's register of expression. As an early crystallization of open source, the sites offered codes that could be used in the further development of designs and fonts on the Internet.
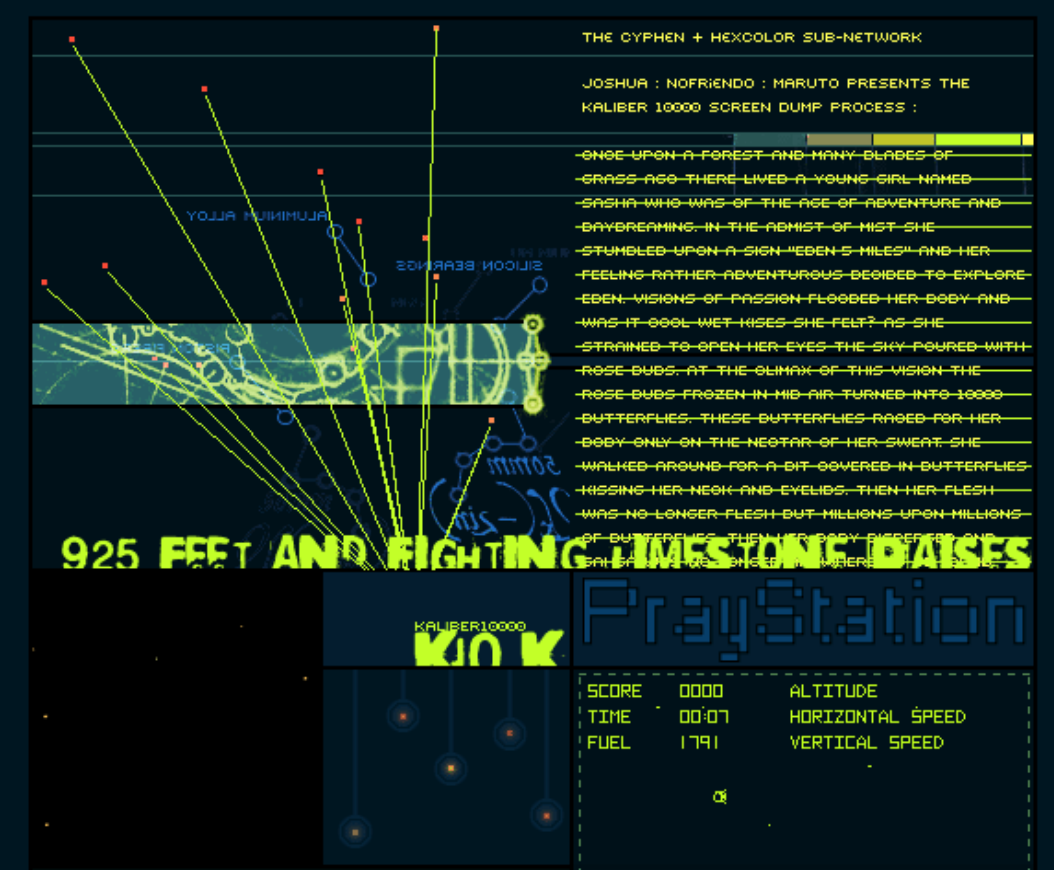
artist Aurelia Harvey's legendary website, entropy8. com. It was launched already in 1994, as one of the first websites to explore the medium as a field for artistic-aesthetic experiments. On the website, use was being made of unorthodox 'html'-codes with an eye toward bringing forth a compelling and experience-colored interaction. The site made its appearance, all things considered, as an exotic web territory with a sampling and expressive aesthetics consisting of graphically processed photographs that were eclectically juxtaposed with differing illusory depth effects and deconstructed typefaces. With visible texture- and layer-on-layer effects, Harvey managed to combine a terse material-related "reality atmosphere" with a new digital finish. The goal was not transparency or easy navigation but opaqueness and artistically processed mediality. Whereas the established sector on the Internet, with the interface industry's spokesmen heading up the pack, was aspiring to provide the user with a sense of direct, unmediated access to data and navigation through "What You See Is What You Get" interfaces, Aurelia Harvey was operating in an intermediate zone situated between clear transparency and opaque mediation. A later example of hypermodal deconstructivism can be spotted on graphic artist Juliet Martin's portfolio website from the late 1990s, which similarly stages an expressive auteur that broke away, in a radical fashion, both from contemporary modernist typographic standards and from the requirements predicating a user-friendly navigation. In Martin's experiments, the classic typographical division of layouts into well-arranged grids has been replaced by a complex and opaque system, with figurative text columns that spread out as patterns on the page. Fragments of text and graphical elements have been drawn from different contexts and put together in novel ways, in the manner of a digital version of the Dadaists' and the cubists' collages. The navigation is cryptic. The contemporary demands for user-friendliness on the Internet have been superseded by alternative and experience-oriented modes of navigating. Through the juxtapositions and collocations, what is being communicated here is a critical manifesto about the digital medium's potentials for free sampling and copying that gave rise to unlimited opportunities for designers but also played a special part, simultaneously, in undermining their copyrights. In the 1990s, when slow transmission speeds placed restrictions on web design, it took, as we know, a long time to download the graphically heavy web pages; this must have been taxing on the users' patience. The objective of the experiments with hypermodal deconstructivism, however, was not to provide easy access to the content but rather to comment on the Internet's current developments and examine the new medium's design register. In this respect, these experiments can be regarded as examples of conceptual typography inasmuch as the sites were commenting, in a number of different ways, on the Internet's current modes of operation and embodied messages that surpassed the functional mission, i.e. that of providing access to content or functions.

\section{DIGITAL CRAFTING AND MEDIA-REFLEXIVE ICON- OCLASM}

Another contemporary experimental tendency on the Internet grows out of a squaring of accounts with the hegemony of printed matter for the sake of conducting an examination of the digital "material", which is comprised exclusively of 0 's and 1-numerals and can be described as a form of "digital crafting" via experimental numerical representation. One of the progenitors in the formative years of the Internet was computer artist and MIT-researcher John Maeda who, in his influential book, Design by Numbers (1999), encouraged artists and designers to learn how to program with an eye toward enabling themselves to create truly innovative forms of expression in the new digital media. Another prominent figure working on the Internet was the programmer, Joshua Davis who, under the umbrella of the websites, Once Upon a Forest and Praystation, launched alternative forms of digital typography and type design and managed also to show how they were programmed. As an early crystallization of open source, Davis offered designers the opportunity of being able to make use of the codes and even to develop them further, on their own websites. $V i a$ the open access, the sites articulated a form of resistance to commercial firms that were regarded as setting the standards and were seeking to gain a monopoly on the Internet. Through the programming of alternative forms of web design and digital typefaces, Davis was inciting designers to circumvent - and to break away from - the standards in order to become independent of software producers and consortia. Through programming, the design tasks could be liberated.

A third theme in the Internet's early development was oriented around what could be called an iconoclastic exploration of the new media and around how experiments with coding served as the jumping-off point for critical objections to the Internet medium as such. The objective here was not, as had been the case in Davis's project, to conjure up new and interesting typographical or interactive expressions but rather to display the symbolic typeface-conformity that the interface shields off 
and covers over, in order thereby to demonstrate the manipulation that was believed to be going on behind the screen, as well as to confront and challenge all the notions of "transparency" that the interface industry was evidently upholding. The experimental objective appears to be crystallizing as a media-reflexive iconoclastic action that was targeted specifically at breaking critically with the established dogmas about simple communication and "transparency" in the Internet medium.

One concrete example of the iconoclastic approach is Eric Rosevear's e13.com, which first appeared at the closing of the 1990s. On the site, the user encounters deconstructed GUI-navigation elements along with hand-drawn scribblings, short snatches of texts and pieced-together typefaces. What can be seen on the front page is an over-weighted and disabled "free-text" search field with a message instructing the user to type in a keyword and click
"Enter". Whatever keyword you might happen to choose, you'll land on a page that says, "Sorry, page not found". The typeface is chopped into pieces and deconstructed and props up the website' non-functional and sampled expressions. Yet another example of the iconoclastic approach can be seen in the work of the Belgian-Dutch duo, Jodi, and specifically on their website, jodi.org, which is constantly being revised and updated. Here, among other things, we are shown code lists with more or less unintelligible names, arranged in a non-transparent circular process that continuously sends the user right back to where he/she started, where swatches of text and typographical elements are "floating around" and constantly changing their location and function. What's really essential on this website is not to provide access to content or functions but rather to put the user into certain intractable situations that stimulate reflection on the web's user-friendliness or -unfriendliness. Jodi.org is pointing out that the

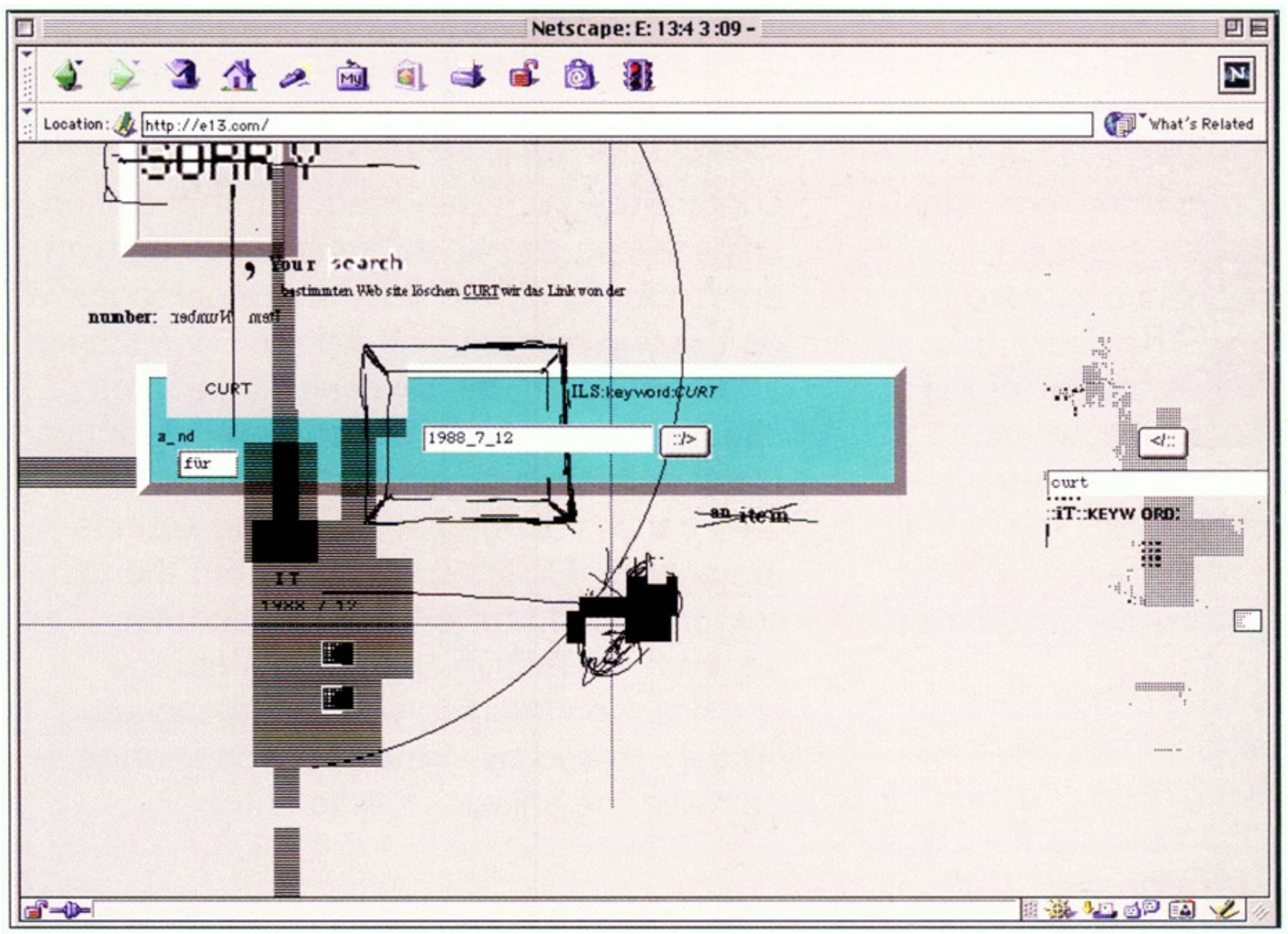

In the middle of the 1990s, Eric Rosevear's site, e13.com, was exploring the web's codes with an avowedly media-critical aim, which deconstructed the web-screen's images and clearly revealed the codes behind the screen. The essential goal of the project was not to achieve interesting or classically aesthetic graphical expressions but rather to display the ideals about transparency and user-friendliness that the interface industry holds aloft but which often proved, in the middle of the 1990s, to fall short on the Internet as a direct consequence of the low transmission speeds and the limitations in the browsers and the programming languages. On the site, Eric Rosevear exhibits and comments critically on the Internet's "user-hostility" through non-transparent interactive sequences and "rigged navigation". 
Internet is a digital structure, a numerical text, over which the user really has no influence but is quite simply compelled to follow the laid-down paths and inevitably find him/herself, along the way, in the thicket of problems and limitations that the medium offers. What is common to the iconoclastic features is that when they were first launched, during the web's formative years, they were all working with rendering the new medium's mediality visible and with exhibiting the "non-transparent transparency" with which the medium was considered to be operating at that time.

\section{THE READER'S SUSCEPTIBILITY}

When we think in an isolated way about the development's external symptoms, it is possible, on the one hand, to regard the experimental features as manifestations of a showdown with the established Internet medium's standards related to expedient communication and functional interaction. Their purpose was not to uphold the conventions but rather to distance themselves from these traditions' narrowing influence so as to make room for a development of both typefaces and typographical layout that would be based on a different kind of dialogue with the viewer. In this kind of practice, the effective jumping-off point is moved away from the "authorized" frames for communication over toward their underlying message. Whereas it is the case within established "normal design" contexts that the web-developer's primary responsibility is to ensure easy access to the content, the sphere of responsibility in conceptual typography is moved over, to a significant degree, toward the viewer's susceptibility in relation to the message. This demands more from the receiver, who is supposed to understand and to decode the content. And it is this susceptibility/non-susceptibility that conceptual design focuses on and thus provokes. Neither the showdown with the established tradition nor the programmatic challenging of the reader's susceptibility are new themes; they can be spotted, for example, in postmodernism's prepress contexts, where radical strategies of grabbing hold of communication, in order to incite the public to become engaged in the text, placed a great deal of weight on the meaning's construction. In line with the postmodern graphic designers, conceptual typography on the Internet is aiming to engage or to challenge the receiver by displaying meaning and web design in novel ways that involve the user as an active participant and simultaneously explore the boundaries of the typography's modes of operation. The examples cited above can be viewed as mirrors of their era and, as such, it is crucial to document them.
The Internet's development has been progressing at a brisk tempo and important phases of the early years of its history have not been documented. In this perspective, what is essential is to describe the development and to describe how conceptual typography has commented on these advances. At the same time, the early experiments fashion the basis for discussions about conceptual typography's contemporary role on the Internet and in other publishing situations.

\section{NORMAL TYPOGRAPHY?}

If we look at the Internet's development as it is transpiring in the present day, we can see that the experimental features have come to be assimilated into "mainstream web design", albeit in a form where conceptual typefaces and graphic elements most often serve as detached effects or aesthetic holds in the form of, for example, deconstructed letters or alternative layouts of web pages that nonetheless do not fundamentally break away from the standards for the layout of web pages that appears to have crystallized in recent years. In synch with the "dot.com" crisis of 2000, what emerged was a rising demand for user-friendliness in both typography and navigation, with an eye toward ensuring the web pages' commercial and market-related status. This created fertile soil for a consolidation of usability principles and established graphic-functional approaches and has brought about, via the enterprises' and the users' sustained requests for easy access to content, a situation where web design appears, in the present day, to have stabilized into a relatively homogenous standard for layout, navigation and typeface choices.

On the other hand, the incidence of experimental features, which was so characteristic of the Internet in its early pioneer years, appears to be diminishing. The mainstream on the Internet appears to have evolved within a pragmatic and, in reality, a rather unaltered approach to design. Web designers all over the world are carrying further a functional tradition which takes its mark in both modernism and usability principles that are being applied on the basis of practical considerations or in response to demands from the surrounding environment, with the upshot that they largely do not deviate from whatever is regarded as being expedient and efficient in the consolidated design traditions and whatever ensures consensus in the established networks of designers. Here we can see cunning implementations of the established traditions, which play a role in securing expedient interaction. However, what we are also seeing here are, all too often, 
rather standardized solutions, among which only experts can spot the differences, solutions that cannot avert the fate of standing in the way of adopting a critical attitude toward the modern heritage and the role that the typographical style is going to play in the time to come. With the rising regimentation of design on the Internet, it seems appropriate to ask: What has become of the experimental features that were moving the boundaries and pleading for change and critical intervention? If we may borrow from Sol LeWitt's dictum that "the idea becomes a machine that makes the art" and replace "art" with "typography", it would then seem appropriate to ask: What is the "idea-machine" supposed to be in contemporary digital typography? What are the artistic, the ideological or the political features that place a question mark beside the typographical tasks and forms today? Is the answer simply "greater standardization"? Or do we also have a need for alternative forms of typography? Experiments with typography have value in themselves because both working with the typeface and the visual result can bring forth new ideas. In our complex mass-communicative society, there can be no doubt that there is still a need for standardization in order to ensure expedient and effective communication, but there is also a need to explore the language of typography and the modes of operation. Here, a continued dialogue concerning the relationship between writing and the ideas behind the text might prove to be necessary. Unlike the heroic functionalist typography-pioneers' self-knowledge and expectations, today's designers do not have unconditional freedom to influence the development of the ever more encompassing communication-landscape. But this is not tantamount to saying that the designers have no influence. It's rather the case that the path to innovation and influence is moving, in the present day, right through a firm grasp of the increasing communications-related complexity, as this manifests itself in the various media and in the typefaces and forms of which we avail ourselves. Here, the Internet is the obvious place for experimentation and is clearly the right place to inquire into how it is possible to explore what typography's role is today and what it ought be in the future. In this connection, the historical documentation is important because it offers insight into how typography has been developing within the compass of a new medium. Additionally, such documentation can serve as the springboard for continued discussions of conceptual typography's role today, both in the printed and the digital media.

\section{NOTES}

1. Dictionary.com, http://dictionary.reference.com/ browse/conceptual+art?s=t (accessed March 2012).

2. See, for example: Peter Osborne (2002). Conceptual Art. Themes and Movements. London: Phaidon and Michael Corris (ed.) (2004). Conceptual Art: Theory, Practice, Myth. Cambridge, Massachusetts: Cambridge University Press.

3. Sol LeWitt (1967). Paragraph on conceptual art, in Artforum (June 1967).

4. See, for example Tony Godfrey (1998). Conceptual Art. London: Phaidon.

5. For a more detailed definition and discussion of the concept of critical design, see, for example: Anthony Dunne (1999). Hertzian Tales: electronic products, aesthetic experience and critical design. London: Royal College of Art computer related design research studio; Anthony Dunne \& Fiona Raby (2001). Design Noir: The Secret Life of Electronic Objects. Basel: Birkhäuser; Uta Brandes (2009). Designtheorie und Designforschung. Paderborn: Wilhelm Fink.

6. Ida Engholm (2003). WWW's designhistorie - websiteudviklingen i et genre- og stilteoretisk perspektiv [WWW's design history - website development in a genre- and style-theoretical perspective.] $\mathrm{PhD}$ dissertation, IT University of Copenhagen, pp. 56-61.

7. For an elaboration in further detail of the design-ideological debate in the Internet's formative years (1993-2003), see also, Ida Engholm (ibid).

8. Jacob Nielsen launched his site, "Useit.com", in 1995, furnishing guidelines for website design and focusing on promoting usability on the web. See also: Jacob Nielsen (2000). Designing Web Usability. Indianapolis, Indiana: New Riders; Jacob Nielsen \& Marie Tahir (2002). Homepage Usability. 50 Websites Deconstructed. Indianapolis, Indiana: New Riders.

9. Jacob Nielsen (2000). Op. cit. p. 15.

10. Michel De Boer (1991). Lecture at the Monotype Conference, London, quoted by Graham Wood in "Too much legibility", Desktop publishing commentary, 7, pp. 8-13.

11. Rick Poynor (1991). Typography now: the next wave. London: Internos, Introduction.

12. Curt Cloninger (2002). Fresh Styles for Web Designers: Eye Candy from the Underground. Indianapolis, Indiana: New Riders.

13. Ida Engholm (ibid), pp. $162 f f$.

14. See also: Lisbeth de Boer et al. (1997). Website Graphics. The Best of Global Site Design. London: Thames and Hudson. 
15. For a further elaboration of Joshua Davis's objectives in the experiments with Flash, see Joshua Davis (2002). Flash to the Core. An Interactive Sketchbook. Indianapolis, Indiana: New Riders.

16. The notion of "media-reflexive iconoclasm" was introduced by Søren Pold and Lars Kiel Bertelsen (2003). “Hvad viser skærmen? Interfacet mellem referentiel og medial transparens". [What's the screen showing? The interface between referential and medial transparency]. Aarhus University. Unpublished manuscript.

\section{REFERENCES}

Brandes, Uta, Erlhoff, Michael, \& Schemmann, Nadine. (2009). Designtheorie und Designforschung. Paderborn: Wilhelm Fink.

Corris, Michael. (2004). Conceptual art: theory, myth, and practice. New York: Cambridge University Press.

Davis, Joshua. (2003). Flash to the core: an interactive sketchbook. Indianapolis, IN: New Riders Pub.

Dunne, A., \& Raby, F. (2001). Design noir: the secret life of electronic objects. Basel: Birkhäuser.

Dunne, Anthony. (2005). Hertzian tales: electronic products, aesthetic experience, and critical design (2005 ed.). Cambridge, Mass.: MIT Press.

Engholm, Ida. (2003). WWW's designhistorie. Website udviklingen i et genre- og stilperspektiv. (Ph.D. afhandling), IT University of Copenhagen, Copenhagen.

Godfrey, Tony. (1998). Conceptual art. London: Phaidon.

Nielsen, Jakob, \& Tahir, Marie. (2001). Homepage usability: 50 websites deconstructed. Indianapolis, Ind.: New Riders.

Nielsen, Jakob. (2000). Designing web usability. Indianapolis, Ind.: New Riders.

Osborne, Peter. (2002). Conceptual art. London ; New York: Phaidon.

Poynor, Rick, \& Booth-Clibborn, Edward (Eds.). (1991). Typography Now - the Next Wave. London, England; New York, NY, USA: Internos Books; Hearst Books International.

Velthoven, Willem, Boer, Liesbeth den, \& Strengholt, GeertJan. (1997). Website graphics: the best of global site design. London; New York: Thames and Hudson.

\section{CORRESPONDENCE}

Ida Engholm, Royal Danish Academy of Fine Arts, Schools of Architecture, Design, and Conservation, Philip de Langes Allé 10, 1435 Copenhagen K, Denmark.

E-mail: ie@kadk.dk

Published online 19 December, 2013

ISSN 1749-3463 print/ ISSN 1749-3471

(C) 2013 Artifact.

Copyright to illustrations in this article resides with the creator unless otherwise noted. Artifact publishes illustrations in accordance with commonly acknowledged fair use of visual materials for non-commercial research purposes. Creators who feel that publication is in violation of copyright or fair use should contact the editors. 